\title{
Methodical approach to the justification of project design decisions on the application of "green" building technologies
}

\author{
Sergei Beliakov* and Anna Kapustkina \\ Moscow State University of Civil Engineering, Yaroslavskoe shosse, 26, Moscow, 129337, Russia
}

\begin{abstract}
The article is devoted to one of the most relevant areas of research in modern Russian conditions - the consideration of issues related to the formulation and justification of methodological approaches to the design of buildings belonging to the category of "green" construction in smart city concept. Designing such facilities includes a comprehensive analysis of the building as a single energy system, and also includes the study of issues related to energy conservation at all stages of the life cycle of the property, the environmental regime of land use, water conservation and wastewater treatment use in the construction of environmentally friendly materials, etc. Planning of any investment and construction project is associated with an analysis of the feasibility of its implementation, taking into account all stages of its life cycle: conceptual study and design, construction, operation, utilization. When planning projects using "green" building technologies, the solution of these problems requires the use of specific approaches and tools. Substantiation of decisions on resource and energy saving in the design of buildings can be carried out on the basis of the following methodological approaches: construction and (or) functional. Based on the presented approaches, the authors have developed a comprehensive algorithm for planning and implementing an investment and construction project using "green" building technologies.
\end{abstract}

\section{Introduction}

The introduction of "green" construction technologies is now becoming one of the main directions for the development of the high-tech segment of the investment and construction sector in Russia. This is facilitated by two key trends: the interest of future property owners in the application of energy-saving technologies and the increase in the competitiveness of projects that use "green" technologies [1-5].

One of the most relevant modern approaches to the development of construction used in developed countries is the design of buildings based on the principle of Triple Zero or ZeroEnergy Building (ZEB) - buildings that provide zero energy consumption. This concept implies the internal sources of energy necessary for the functioning of the building, the

\footnotetext{
Corresponding author: serj-bel@yandex.ru
} 
absence of harmful emissions and the use of fully recyclable materials for construction, which allows to achieve the absence of harmful waste [6-10].

Today, this approach is one of the main directions of development of modern construction in Europe. For the first time, this principle was applied in the construction of a two-story office building in Berlin (Germany), designed so that the total annual energy consumption was lower than revenues from renewable energy sources.

One of the significant projects built on the ZEB principle is an unusual house of $220 \mathrm{sq}$. $\mathrm{m}$. built in the countryside in Norway. It is positioned by the authors of the architectural solution as a family residence, but first of all it is a demonstration project that helps to better understand the principles of "green" building. Architectural and planning solutions of the building are designed taking into account the use of renewable energy sources. The house has a characteristic southeast orientation for more efficient operation of solar panels on the roof. The project provides for the drilling of geothermal wells, which allows to get some of the energy from underground sources. There is enough power supply to provide the whole house, and an electric vehicle is charged with surplus all year round. Windows and solid walls alternate so that a balance is maintained between the lighting, the views of nature and the exit to the outside. The issues of heating and cooling have been resolved due to the correct location of the glass surfaces, orientation and geometry of the house. Materials are selected on the basis of thermal characteristics, requirements for microclimate and aesthetic qualities.

One of the most technologically advanced buildings today, built on the basis of this approach, is the Zero Carbon Building, which is located in Hong Kong in the Kowloon Bay integrated development area. This project serves as real proof that the building can meet Triple Zero standards in different climatic conditions. Zero Carbon Building is a zero carbon building. It produces more energy than it consumes, while the excess energy is sent to the city's power grid. The building is located in such a way that its walls and roof receive the maximum possible amount of solar energy. Most of the external structural elements are made of glass, which gives access to natural light. The object also has a slope, due to which air streams moving along the surface get into special traps and help the operation of ventilation systems. As one of the types of biofuels used waste oil after cooking. More than $50 \%$ of the internal territory of the complex is occupied by the green zone, 3.7 thousand trees of the complex provide shade.

In Russia, no buildings that fully meet the concept of Triple Zero have been built to date, however, there is already considerable experience in "green" building.

In particular, the plant of the Swedish concern SKF for the production of railway bearings in the industrial zone "Borolevo-2" of the Tver region became the first building in Russia certified according to the international "green standard". Among the "green" technologies used at the facility are the following:

- Heat recovery. Energy-efficient chillers with the utilization of waste heat for heating the building are used for the system for the preparation of process cold water.

- Automated engineering systems management system. Allows you to conduct a detailed analysis of energy consumption.

- Daylight. Providing natural light to $90 \%$ of all building areas during daylight hours.

- Ventilation on demand. Provides optimal working environment and energy efficiency.

- Carbon monitoring systems.

- Recycling water. The innovative process of vacuum distillation of water provides $100 \%$ reuse of water during phosphating. For watering lawns only rainwater is used.

Another example is the Ducat Place III building, located in Moscow. It is a 14-story business center operated by Hines. This complex has become the second building in Russia certified according to the international "green standard" and the first commercial property 
certified according to the BREEAM standard. Among the "green" technologies used at the facility are the following:

- Energy efficient lighting. Ordinary lamps in the office center are replaced by energy-saving. In the building, specially developed programs of computerized operation of light systems that take into account natural lighting are applied.

- Motion sensors. In the bathrooms installed motion sensors.

- Optimized the operation of elevators and air conditioning systems. This reduced the energy consumption of the building by $35 \%$.

- Separate waste collection. The building has a full cycle of waste disposal (in the absence of a citywide recycling program in Moscow at the moment). The operating company organized a systematic waste disposal, concluding contracts with private contractors for recycling paper, cardboard, plastic, metal, glass, electric lamps, cartridges and batteries, which are so necessary for the life of the offices.

- High-tech car parking. The project has the highest ratio of area and parking for the center of Moscow.

\section{Materials and Methods}

Considering the modern Russian practice of construction, it should be noted that a number of factors hinder the widespread use of "green construction" technologies:

- $\quad$ significantly lower compared to European countries, the cost of energy;

- insufficiently developed culture of environmental responsibility;

- insufficiently developed regulatory framework in the construction and operation of real estate [11-14].

Also one of the key obstacles to attracting investors and stimulating "green building" in Russia is the insufficient level of scientific and methodological development of approaches to the design and construction of energy-efficient buildings. One of the most relevant areas of research is the consideration of issues related to the formulation and justification of methodological approaches to the design of buildings belonging to the category of "green" construction. It is important to note that the design of such objects includes a comprehensive analysis of the building as a unified energy system, and also includes the study of issues related to energy saving at all stages of the life cycle of the property, the environmental regime of land use, water saving and water purification, transportation, use in the construction of environmentally friendly materials, etc. $[15,16]$

Planning of any investment and construction project is associated with an analysis of the feasibility of its implementation, taking into account all stages of its life cycle: conceptual study and design, construction, operation, utilization. When planning projects using "green" building technologies, the solution of these problems requires the use of specific approaches and tools.

When designing "green" construction projects, the following key aspects of the project are subject to comprehensive consideration:

- town planning (choice of building location taking into account climatic conditions, landscape, existing buildings in the area of proposed construction, use of underground space, etc.).

- space-planning (compact form in the plan, flexible planning solutions, functional zoning of premises, including the temperature and humidity parameters of the microclimate, etc.). 
- constructive (use of resource- and energy-saving building materials and structures that have strength, stiffness, crack resistance, with durability, safety, rational operating costs).

- environmental (compliance with the requirements for insolation, noise protection of the premises, the architectural appearance of the building must be in harmony with the environment, the use of environmentally friendly materials in projects, reduction of waste, etc.).

- engineering (application of technical solutions and equipment to eliminate or reduce excess costs for heating, cooling and ventilation of premises, excessive water consumption and lighting, the introduction of new engineering systems, energy sources, equipment, instrumentation, elimination of losses in housing and public utilities transportation of heat, energy, water, etc.). [17]

The evaluation of the effectiveness of "green" building projects should be based on methods that allow evaluating the effects of introducing new design solutions or innovative engineering systems in the project in an economic (increase in initial investment and construction cost of the facility), environmental (environmental impact of the facility, energy efficiency and etc.) and social (improving the quality of life of the population, creating an accessible environment for people with disabilities, etc.) aspects. [18-20]

Taking into account the above principles, the rationale for decisions on resource and energy saving in the design of buildings can be carried out on the basis of the following methodological approaches: building and (or) functional.

In the building approach, the building is considered as a building object - a set of spaceplanning, design solutions, construction methods (technologies, machines and mechanisms, quality, duration of works, etc.), i.e. Attention is focused on the design and construction stages. At the same time, reserves of resource and energy saving are formed by reducing the energy intensity of the construction of the building, however, the effect at the stage of building operation is practically not taken into account. For the construction approach in a generalized form, the objective function of the resource and energy efficiency of design solutions can be written in the form:

$$
E_{C}=F\left(S_{i}+C_{i}+O T_{i}\right)
$$

where $E_{c}$ is the indicator of resource and energy efficiency of the design solution for the construction approach;

$S_{i}, C_{i}, O T_{i}$ - indicators of space-planning, constructive decisions, organizational and technical measures during construction, providing the adopted in the project characteristics of resource and energy saving.

Within the framework of the functional approach, the building is a commodity on the real estate market with specified consumer characteristics: utility, durability, originality and others, including resource and energy efficiency, which in design are achieved through architectural and construction and engineering (heating, ventilation, air conditioning, power supply, etc.) solutions.

Thus, the functional approach is based on the operational characteristics of capital construction objects. The functional approach allows to solve the problem of "deferred effect" from the implementation of measures of resource and energy saving in the design and construction of buildings.

In accordance with the functional approach, the assessment of the effectiveness of resource and energy saving solutions used in projects should be made on the basis of the requirements of operation (consumer):

$$
E_{e}=B_{1} / B_{2}
$$


where $E_{e}$ is the indicator of resource and energy efficiency of operation;

$B_{l}$ is the resource and energy consumption of the building-analogue (base variant);

$B_{2}$ - resource and energy costs for the designed object.

To conduct a comprehensive assessment of "green" building projects, it is necessary to conduct an economic, environmental and social assessment of the project's effectiveness.

To assess the economic efficiency of the most appropriate method is the method of estimating the cost of the life cycle of the building, since this method allows to take into account the economic effect obtained during the operation of the building. The basis of this method is the assessment of the total cost of the design solution of the future efficient building, which will ensure low cost of ownership over the entire life cycle of the object. The final criterion for evaluating an effective building is the present value of ownership, equal to the ratio of the total value of the object to its planned period of operation.

The formula for calculating the cost of the life cycle of the object based on the results of a comprehensive assessment of energy efficiency is as follows:

$$
C_{L C}=P_{1} * E+P_{2} * F *\left(T_{r}+T_{o}\right) * S * E,
$$

where $\mathrm{C}_{\mathrm{LC}}$ - the cost of life cycle of the object;

$P_{l}$ - the amount of investment costs;

$E$ - the discounting factor,

$P_{2}$ - the sum of variable costs;

$F$ - correction factor that takes into account the estimated class of energy efficiency of the building;

$T_{r}$ - the frequency of repairs;

$T_{o}$ - planned terms of equipment replacement;

$S$ - coefficient taking into account seasonality.

\section{Results}

Based on the presented approaches, the authors developed a comprehensive algorithm for planning and implementing an investment and construction project using "green" building technologies (Figure 1).

As an addition to this approach, dynamic methods of analysis and evaluation are used, traditionally used in evaluating the effectiveness of projects, on the basis of which modelling of the main cash flows of income and expenses for the period under review is carried out, and static and dynamic performance indicators are calculated. Compared to static methods, dynamic methods provide a more accurate estimate, since they allow taking into account when evaluating the variability of parameters over time using the discount rate. These indicators are net present value, discounted payback period and internal rate of return. 


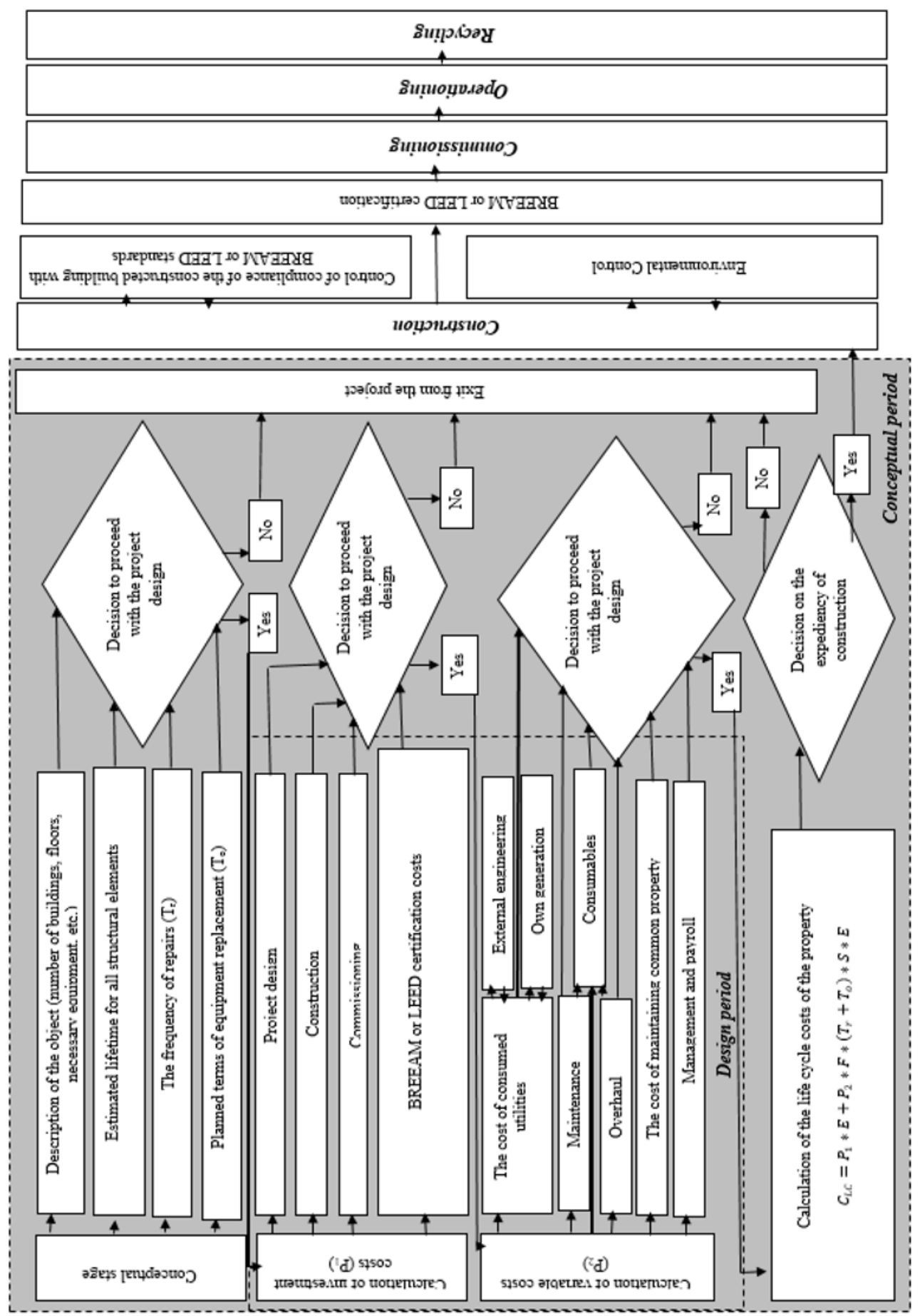

Fig. 1. Comprehensive algorithm for planning and implementing an investment and construction project using "green" building technologies. 


\section{Conclusions}

The approach presented in this article to the assessment and justification of design solutions for "green" construction and the integrated algorithm based on it for planning and implementing investment and construction projects can be used in practice to increase the effectiveness and sustainability of projects of various functional purposes, scope and complexity.

Since the calculation algorithm in this method is universal, it can be applied to any "green" building projects, regardless of what technical decisions were made at the design stage, what materials and equipment are used in construction.

Analysis of the life cycle cost of a building can be carried out for buildings of any type existing and new, residential and public, individual and multi-family. In addition, it is possible to evaluate performance for different groups of stakeholders. For example, for a developer or investor interested in returning their investments, based on the initial costs and analysis of the current situation in the real estate market and marketing research, it is possible to calculate the cash flows from the project over time.

\section{References}

1. A. Murzin, Real estate: economics, evaluation and development (Phoenix, Rostov on Don, 2013)

2. G.M. Solodikhin, I.K. Yazhlev, Volga scientific journal, 3 (31) (2014)

3. L. Girya, S. Sheina, P. Fedyaeva, Journal of Applied Engineering Research, 8 (2015)

4. S. Sheina, E. Minenko, Real estate: economics, management, 2 (2015)

5. A.Yu. Reteyum, Architecture and construction of Russia, 8 (2014)

6. G. Sternik, S. Sternik, N. Tulinova, Real Estate Development (Prospekt, Moscow, 2016)

7. A. Yudina, Technological processes in construction (Academy, Moscow, 2013)

8. P.G. Graboviy, Examination and inspection of the investment process and operation of real estate (Prospekt, Moscow, 2012)

9. P.G. Graboviy, Economics and management of real estate (Prospekt, Moscow, 2012)

10. D. Ben-Shahar, Y. Deng, E. Sulganik, Journal of Housing Economics, 18-1 (2009)

11. V. Leonov, V. Denisov, V. Sedykh, S. Novikov, BST, 7 (2012)

12. A.L. Bolsherotov, Housing construction, 44 (2011)

13. M.Y. Slesarev, T.V. Kuzovkina, Ecology of urbanized territories, 18 (2014)

14. S.V. Sokolov, V.N. Sedih, S.V. Novikov, V.V. Aleksashina, BST 7 (2011)

15. C. Ketels, The Cluster Initiative Green Book (Christian, St Peterburg, 2003)

16. E.V. Sazonov, V.V. Smolyaninov, VGASU Academic Herald. Construction and Architecture, 3(19) (2010)

17. T.I. Iskanderov, M.R. Kuchkarova, Hygiene and Sanitary, 4 (2004)

18. L.V. Vlasenkov, Matec web of conferences, 106 (2017)

19. I.P. Pryadko, International Journal of Applied Engineering Research, 21 (2015)

20. T.Y. Ovsiannikova, M.N. Nikolaenko, IOP Conf. Series: Materials Science and Engineering, 71 (2015) 